\title{
A New Method for Measuring Apparent Volume of Iron Ore Pellets in Conjunction with Determination of the
}

\section{Swelling Index*}

\author{
By Yasuo OMORI** and Eiki KASAI**
}

\begin{abstract}
Synopsis
Swelling index provides a vital information on pellet behavior in the blast furnace. This note describes a mercury-free method for measuring the apparent volume of iron ore pellets. The method consists of determining the weight with a balance of either one or more pellets immersed in water after being treated with aqueous solution of sodium-oleate and kerosine. The apparent volume of the sample is calculated from the known density of water. For reasons of environmental pollution, this method is particularly recommended for testing in a laboratory where swelling test is conducted.
\end{abstract}

\section{Introduction}

Swelling index provides a vital information on pellet behavior in the blast furnace. A method according to JIS (the Japanese Industrial Standard) ${ }^{1)}$ specifies the index in terms of change in apparent volume of pellets before and after swelling under a specified reduction condition. The apparent volume of a pellet is determined by the weight recorded on a balance when the sample is depressed below the surface of mercury. For reasons of environmental pollution a mercury-free method has been urgently required. A new method proposed by the present note is based on weighing in water after the pellet is treated with sodium-oleate aqueous solution and kerosine instead of mercury. The value of apparent volume measured by the method indicates a good agreement with that by the mercury replacement method.

\section{Principle}

The sodium-oleate has been used as collector for hematite ore in the field of iron ore flotation technology. Sodium-oleate $\left(\mathrm{NaO} l: \mathrm{CH}_{3}\left(\mathrm{CH}_{2}\right)_{7} \mathrm{CH}=\mathrm{CH}\right.$ $\left.\left(\mathrm{CH}_{2}\right)_{7} \mathrm{COONa}\right)$ is known as anion type interfacial active agent and has hydrophilic and hydrophobic radicals. Flotation ratio of hematite ore in the sodium-oleate aqueous solution shows higher value in a wide range of $\mathrm{pH} 2$ to $10 .^{2)}$ The reason is recognized as follows: zeta electric potential of hematite ore indicates positive value in the acid range, ferric ion on the surface of hematite reacts with the hydrophilic radical of oleate ion to form an ionic bond, whereas in the basic range, a strong coordinate bond is formed between the ferric ion and the oleate one. ${ }^{3)}$ As a result, surface wettability of hematite ore decreases and bubbles are entrapped at the interface between the hematite surface and the aqueoussolution. Consequently, the hematite ore can be floated.

The present method aims to utilize the following characteristics of the two liquids: penetration of water into pellets at weighing stage is prevented by the strong chemisorption in a basic range of $\mathrm{pH}$ (concentration of $\mathrm{NaO} l$ in aqueous solution, $2 \times 10^{-2} \mathrm{~mol} / l$ and $1 \times 10^{-3} \mathrm{~mol} / l$ correspond to the values of $\mathrm{pH} 10.2$ and 9.2 , respectively), and kerosine is used in order to prevent penetration of water into large fissure or crack of the pellet which is formed during gaseous reduction with $\mathrm{CO}$ or $\mathrm{H}_{2}$.

\section{Measurement Procedure and Experimental Results}

For apparent volume measurement, three kinds of pellets were used: dense acid pellets (A) and porous acid pellets $(B)$ in the size range of $11 \sim 13 \mathrm{~mm}$ and reduced pellets $\left(\mathrm{A}^{\prime}\right)$ which were obtained after the reduction of (A) pellets in accordance with JIS swelling test. Table 1 presents apparent densities and porosities of these sample pellets.

Six series of procedures for the pretreatment by means of sodium-oleate aqueous solution with or without successive treatment by kerosine were examined. These procedures are demonstrated in Fig. 1. As shown in Fig. 2, apparent volume of the samples was derived by measuring buoyancy of three pellets. As a preliminary test, weighing of the sample in water is conducted with immersion distance ranging from 70 to $920 \mathrm{~mm}$. No significant difference was observed between values of measured apparent volume. Consequently, the immersion distance for weighing was kept as $70 \mathrm{~mm}$ throughout the succeeding experiments.

The value of apparent volume according to the respective procedure shown in Fig. 1 is presented in Table 2 in comparison with that of mercury replacement method. The results according to procedure (c) for pellets (B) and (A) suggest a considerable penetration of water into the pellets. On the other hand, good agreement was obtained between the volumes measured according to procedure (f) and that by the mercury replacement method even for pellets $\left(\mathrm{A}^{\prime}\right)$. In case of procedure (f), the effect of the liquids for

Table 1. Apparent densities and porosities of the pellets used.

\begin{tabular}{c|cc} 
Pellets & $\begin{array}{c}\text { Apparent density } \\
\left(\mathrm{g} / \mathrm{cm}^{3}\right)\end{array}$ & $\begin{array}{c}\text { Porosity } \\
(\%)\end{array}$ \\
\hline A & 3.82 & 26.1 \\
B & 3.78 & 31.3
\end{tabular}

* Presented to the 106th ISIJ Meeting, October 1983, S784, at Akita University in Akita. Manuscript received March 7, 1984. (C) 1984 ISIJ

** Research Institute of Mineral Dressing and Metallurgy, Tohoku University, Katahira, Sendai 980. 
Table 2. Comparison between $\mathrm{NaOl}$ aqueous solution methods with various procedure (a) to (f) and mercury method for volume measurement of pellets.

\begin{tabular}{|c|c|c|c|c|c|c|c|c|}
\hline Sample & (1) & (2) & (3) & $(4)$ & (5) & (6) & (7) & (8) \\
\hline Kinds of pellets & (A) & (A) & (A) & $\left(\mathrm{A}^{\prime}\right)$ & (B) & (B) & (B) & $\left(\mathrm{A}^{\prime}\right)$ \\
\hline$V_{\mathrm{Hg}}\left(\mathrm{cm}^{3}\right)$ & 3.43 & 3.32 & 3.48 & 3.54 & 3.62 & 3.68 & 3.64 & 3.55 \\
\hline Method & (a) & (a) & (a) & (e) & (e) & (d) & (a) & (f) \\
\hline$V_{\mathrm{NaO} l}\left(\mathrm{~cm}^{3}\right)$ & 3.13 & 3.01 & 3.21 & 3.14 & 3.11 & 3.18 & 3.10 & 3.51 \\
\hline$V_{\mathrm{Na} O} / V_{\mathrm{Hg}}(\%)$ & 91.2 & 90.8 & 92.3 & 88.7 & 85.9 & 86.4 & 85.2 & 98.9 \\
\hline Method & (b) & (b) & (b) & & & & & \\
\hline$V_{\mathrm{NaOl}}\left(\mathrm{cm}^{3}\right)$ & 3.16 & 2.99 & 3.19 & & & & & \\
\hline$V_{\mathrm{NaOl}} / V_{\mathrm{Hg}}(\%)$ & 92.0 & 90.0 & 91.7 & & & & & \\
\hline Method & (c) & (c) & (c) & & & & & \\
\hline$V_{\mathrm{NaOl}}\left(\mathrm{cm}^{3}\right)$ & 3.25 & 3.13 & 3.29 & & & & & \\
\hline$V_{\mathrm{NaOl}} / V_{\mathrm{Hg}}(\%)$ & 94.7 & 94.3 & 94.5 & & & & & \\
\hline
\end{tabular}

(a)

\begin{tabular}{|c|}
\hline \multicolumn{2}{|c|}{ Drying } \\
\hline $\begin{array}{c}\text { Weighing } \\
\text { MI }\end{array}$ \\
\hline $\begin{array}{l}\text { Weighimg } \\
\text { in water } \\
\text { M2 }\end{array}$ \\
\hline
\end{tabular}

(b)

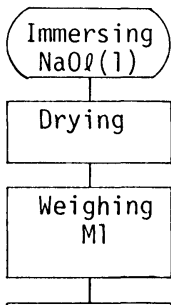

\section{Weighing \\ in water}

M2 (c)

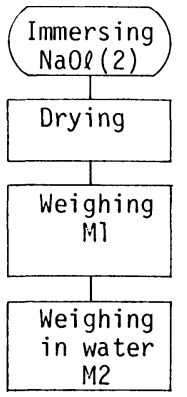

(d)

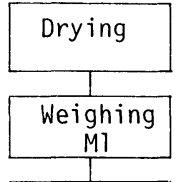

Weighing
in NaOl (1) M2

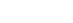

(e)
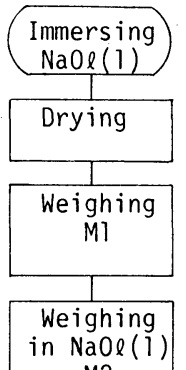

$$
\begin{array}{rlrl}
\mathrm{VNaOl}_{\mathrm{Na}} & =(\mathrm{Ml}-\mathrm{M} 2) / \rho_{\mathrm{H}} \mathrm{O} & \left(\mathrm{cm}^{3}\right) \\
\text { Apparent density }((\mathrm{a}) \text { to }(\mathrm{e})) & =\mathrm{Ml} \rho_{\mathrm{H}_{2} \mathrm{O}} /(\mathrm{MI}-\mathrm{M} 2) & \left(\mathrm{g} / \mathrm{cm}^{3}\right) \\
\text { ". } & \mathrm{f}) & \mathrm{MO} \rho_{\mathrm{H}_{2} \mathrm{O}} /(\mathrm{Ml}-\mathrm{M} 2) & \left(\mathrm{g} / \mathrm{cm}^{3}\right)
\end{array}
$$

(Immersing technique into $\mathrm{NaOl}$ aq. solution shall be conducted) under reduced atomosphere excepting in case of $(f)$. Drying : $105 \pm 5^{\circ} \mathrm{C}, 2$ hours

$\mathrm{NaOl}(1): 2 \times 10^{-3} \mathrm{~mol} / 1$

$\mathrm{NaOl}(2): 10^{-2} \mathrm{~mol} / \mathrm{l}$

Fig. 1. Various methods by using $\mathrm{NaO} l$ aqueous solution with or without kerosine for volume measurement of pellets.

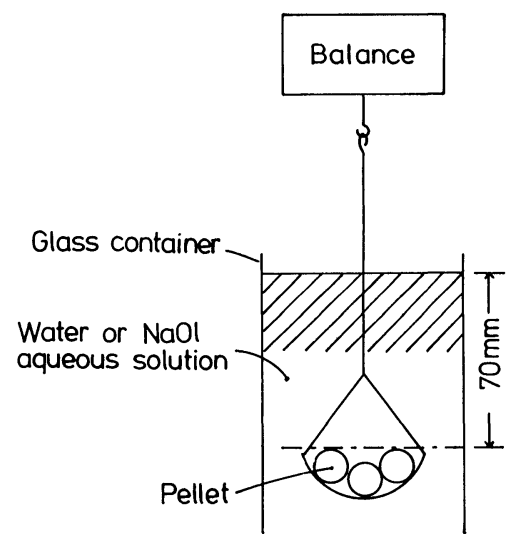

Fig. 2. Weighing procedure of pellets in liquids.

pretreatment in the vicinity of pellet surface is schematically illustrated in Fig. 3. It may be understood from the above-mentioned results that penetration of

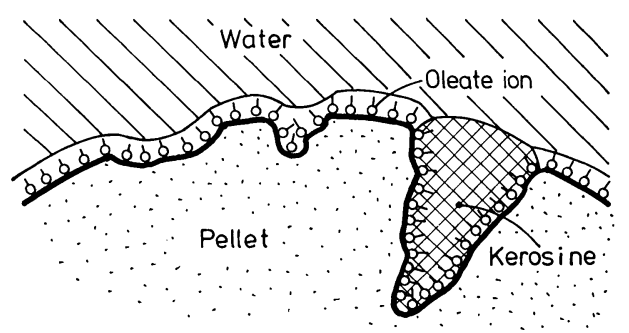

Fig. 3. Schematical illustration on the effect of the oleate ion and kerosine in the vicinity of the pellet surface.

water into finer crack is prevented by the oleate ion chemisorbed and penetration into larger crack by kerosine. This effect contributes to give a good result with procedure (f).

According to the preliminary test experiences, overflow of the sodium-oleate aqueous solution out of a glass container should be paid attention during immersion of the pellets into the solution at vacuum 
operation (about $50 \mathrm{mmHg}$ ) because of vigorous formation of bubbles. Additionally, the following factors may have influence on the accuracy of measured value based on the recommended method (f):

i) decomposition or dissociation of the oleate compound at the drying stage,

ii) change in the measured value by the lapse of immersion time into either the solution or kerosine, and

iii) separation of the kerosine from the crack of the pellets.

Drying under reduced atmosphere, standardizing the immersing procedure into the liquids and selecting kerosine with optimum viscosity are thought to be as the countermeasures for the problems (i), (ii) and (iii), respectively.

\section{A Proposed Method for Apparent Volume Measurement of Pellets}

A method is proposed for apparent volume measurement in accordance with the procedure (f) mentioned above as follows:

1) immerse the sample pellets into $\mathrm{NaO} l$ aqueous solution $\left(10^{-2} \mathrm{~mol} / l\right)$,

2) dry the sample either at $105 \pm 5^{\circ} \mathrm{C}$ or under reduced atmosphere and cool $30 \mathrm{~min}$ in a desiccator,

3) weigh in air $\left(M_{0}\right)$,

4) immerse into kerosine,

5) remove excess kerosine from the sample surface by rolling them on gauze,

6) weigh in air $\left(M_{1}\right)$,

7) weigh in distilled water $\left(M_{2}\right)$,

8) measure the temperature of the water $(T)$. Apparent volume and apparent density of the pellets are calculated according to the following equations (1) and (2), respectively:

Apparent volume $=\left(M_{1}-M_{2}\right) / \rho_{\mathrm{H}_{2} \mathrm{O}}$

$$
\text { Apparent density }=M_{0} \rho_{\mathrm{H}_{2} \mathrm{O}} /\left(M_{1}-M_{2}\right)
$$

where, $\rho_{\mathrm{H}_{2} \mathrm{O}}$ : density of distilled water at the temperature $T(\mathrm{~K})$.

\section{Summary}

In order to develop the method for measuring apparent volume measurement of pellets without using mercury, we have proposed a method by weighing in water after pretreating the pellets with aqueous solution of sodium oleate and kerosine. The measured value was found to be in good agreement with that by the mercury replacement method even for the pellets after gaseous reduction. A proposal of measuring method in accordance with procedure (f) is presented.

A cooperative research according to this method is now undertaken by Sub-Committee of Physical Testing of Iron Ores, Japan Iron and Steel Federation in order to determine the swelling index of various kinds of pellets, and assessment of the test results and test conditions for standardizing the method is in progress.

\section{Acknowledgements}

The authors wish to express their sincere appreciation to Professor S. Usui, Assistant Professors T. Yamamoto and H. Sasaki of Research Institute of Mineral Dressing and Metallurgy, Tohoku University for their valuable comments and suggestions. This study was carried out under the support of the 54th Committee (Ironmaking), the Japan Society for the Promotion of Science (Gakushin).

\section{REFERENGES}

1) J1S M 8715-1976, "Method for Measuring the Swelling Index of Iron Ore Pellets", Japan Society for Standardization, 1976, Tokyo.

2) F. Yamamoto, J. Sumimoto, N. Imanishi, I. Fujita and S. Mukai: Preprint of MMIJ Meeting, (1982), 389.

3) S. Usui and S. Takeda: Preprint of MMIJ Meeting, (1982), Session No. 9-6. 